\title{
20 Years of Hypertension Research Using Genetically Modified Animals: No Clinically Promising Approaches in Sight
}

\author{
Lavinia Stingl ${ }^{1}$, Manfred Völkel ${ }^{2}$ and Toni Lindl ${ }^{1}$ \\ ${ }^{1}$ Institut für angewandte Zellkultur, Munich, Germany; ${ }^{2}$ Tierversuchskommission Nordbayern, Regierung von Unterfranken, \\ Würzburg, Germany
}

\begin{abstract}
Summary
The incidence of essential or primary hypertension is increasing, especially in the northern hemisphere, but although the disease displays clear symptoms, its aetiology appears very complex, and thus no causal treatment is available yet. In the 1990's, genetically modified animals (GMO) were considered to be the key to solving this problem of high complexity. However, until now, although a few approaches have shown that old, well-known drugs have a positive effect (decrease of blood pressure) on such animal models of hypertension, no approach has appeared in the literature of this area of research which might indicate a direct connection between GMO and a therapeutic strategy to treat or prevent this type of hypertension in humans. Instead, criticism of the GMO approach has accumulated in the last years, arguing that it is misleading as this disease does not have a monogenic cause and so complementary regulatory mechanisms could prevent the true identification of the function of the modified genes. Furthermore, the technology is best developed in mice, whose physiology of blood pressure is different from that of humans. Because of species specificity, it is not easy to extrapolate the results from animal models of hypertension to human hypertension. Also, in the years 2000 to 2004 a reorientation of the technology and the aims of this kind of research took place. Therefore, although these approaches are without exception deemed "very promising" in the literature, it cannot be expected that research on GMO will make any contribution to a new therapeutic strategy in the near future.
\end{abstract}

Keywords: primary hypertension, genetically modified animals-GMO, diagnostic and therapeutic application, target molecules

\section{Introduction}

Blood pressure of at least $140 \mathrm{~mm} \mathrm{Hg}$ systolic and $90 \mathrm{~mm} \mathrm{Hg}$ diastolic is the hallmark of arterial hypertension. The cause is only known in about $10 \%$ of patients: renal disease, tumours, drugs or diabetes. This so called secondary hypertension may normalise when the underlying disease is treated. In about $90 \%$ of patients, no organic cause for the increased blood pressure can be identified, and these cases are termed primary or essential hypertension. This is a multifactorial disease in which genetic and environmental factors interact in a complex way. The consequences of untreated hypertension are arteriosclerosis, coronary heart disease, heart attack, heart failure, renal failure, arterial occlusion and stroke.

Blood pressure is regulated by many physiological systems that have pleiotropic effects and interact in a complex way, including the renin-angiotensin-aldosterone system (RAAS), the vegetative nervous system, the kinin-kallikrein-system (KKS), the vascular endothelium, natriuretic peptides, and dopamine receptors. Many genes that may influence blood pressure have been identified by systematic analysis of the human genome and by using animal models (Agarwal et al. 2005; Marteau et al., 2005; Mullins et al., 2006). However, the underlying molecular mechanism that leads to the development of primary hypertension is not yet clear. Almost all results and therapeutic approaches up until now have been gained from in vitro experiments and animal models for hypertension research, e.g. the spontaneously hypertensive rat, the Milan rat and the Dahl rat. These animal models were selected because of their hypertonic phenotype, which may have complex causes.

Genetic manipulation offers a complementary strategy, allowing one gene to be selectively overexpressed (transgene technology), underexpressed (knock down technology) or turned off (knock out technology), either in selected tissues or in all the 
tissues that normally express it. The knock out technology is easier to apply in mouse than in rat (Tesson et al., 2005). The knock down technology (RNAi) has been employed successfully in both mice and rats (melo et al., 2005).

Insights gained from such animal experiments should help us understand the interactions between the blood pressure regulating systems. With the help of GMO the researchers also aim to identify new, therapeutically relevant targets (e.g. receptors or pharmacologically susceptible regions on the DNA or on proteins), as most hypertensive patients cannot control their blood pressure with the currently available drugs (Scott et al., 2006).

This study aims to investigate whether and in what quantity and quality, the last 20 years of research with GMO have been able to establish, introduce or support new therapies for human primary hypertension.

\section{Methods}

In this study, we searched PubMed for literature indicating a connection between hypertension and transgenic and knock out animal models. For this, all reviews in English between 2000 and June 2007 that included the following key words were assessed: "hypertension knock out animal", "hypertension transgene animal", "hypertension knock down animal", "hypertension overexpressed animal". Finally all relevant subheadings (see Results sections: A I-IV) were combined with these terms. All articles (reviews and experimental reports) with indications of clinical relevance in the abstract were considered, including those that described suggestions for therapies for the sequelae of hypertension. Articles with the following contents were excluded: limited connection to hypertension (e.g. glaucoma, alcoholic cardiomyopathy), possible improvements but not therapies of the consequences of hypertension, other diseases in which hypertension only plays a secondary role (e.g. obesity, diabetes, renal disease, arteriosclerosis, metabolic syndrome, menopause, pregnancy, drug use), other forms of hypertension (e.g. pulmonary hypertension, portal hypertension, monogenic hypertension, malign hypertension), which are entirely unrelated to primary hypertension. The approach is described in detail in our original study, commissioned by the Fund for Animalfree Research in Zurich and presented to that organisation in the form of a detailed report. All articles that were found by this search strategy, which reported on transgenic and knock out animal models and included possible references to humans in their abstracts were analysed. Those publications that contained a reference to a possible therapeutic strategy in humans or that contained analogies to humans were analysed more thoroughly by reading the entire study. Where no references to humans were found or the articles dealt only with basic research, the reports were not further analysed.

Beside the references to humans, the importance of a publication was deemed to correlate with the frequency of its citation in the scientific literature. Hence, citation frequencies for all publications within our search strategy were retrieved.

\section{Results}

The PubMed search resulted in a total of 577 reviews. Of these, 115 reviews published between 2000 and June 2007. The abstracts of these reviews were analysed to determine whether they described a connection between transgenic or knock out animals and primary hypertension. Reviews from animal experiments before 2000 were not considered. At this time, a reorientation occurred with regard to such animal experiments, so that earlier publications and their citations have become practically meaningless. The selected reviews were categorised according to their research focus. $56 \%$ of the articles dealt with basic research (no evidence of possible applications of the results), $44 \%$ with applied research (possible applications of the results for clinical use) and $0 \%$ with clinically orientated research (direct applications of the results from GMO to humans). The number of citations and the citation index (citation frequency / time) were determined for these reviews and are summarised in Table 1. There were no apparent trends regarding the research content or emphasis.

The PubMed search was than expanded by one search term (A I-IV with subitems) to categorise all relevant sources (reviews and original articles) between 2004 and 2007 regarding primary hypertension and GMO. All known physiologically active blood pressure regulating systems were considered. This search delivered 349 articles with regard to primary hypertension. $78 \%$ dealt with basic research, $22 \%$ focused on applied

Tab. 1: Summary of the reviews with citation number and citation index*

\begin{tabular}{lllll}
\hline $\begin{array}{l}\text { Reviews } \\
n=115\end{array}$ & $\begin{array}{l}\text { Citation index } \\
\text { (no citations) }\end{array}$ & $\begin{array}{l}\text { Citation index } \\
0.1-0.7 \\
\text { (1 to } 5 \text { citations) }\end{array}$ & $\begin{array}{l}\text { Citation index } \\
0.8-1.4 \\
(6 \text { to } 10 \text { citations) }\end{array}$ & $\begin{array}{l}\text { Citation index more than 1.4 } \\
\text { (more than 10 citations) }\end{array}$ \\
\hline $\begin{array}{l}\text { mainly applied research } \\
\mathrm{n}=66\end{array}$ & 21 & 4 & 9 & 32 \\
\hline $\begin{array}{l}\text { mainly basic research } \\
\mathrm{n}=49\end{array}$ & 19 & 6 & 5 & 19 \\
\hline
\end{tabular}

\footnotetext{
* The index was calculated as the number of citations divided by the time between year of publication (up to 2000) and 2007. The results were divided into 4 categories, from citation index 0 ( 0 citations in a maximum of 7 years) to more than 1.4 (10 citations in a maximum of 7 years). At least one citation per year was required to achieve a citation index of 1 .
} 
research, but none described direct applications of the results gained with GMO in humans.

All retrieved publications with connections between primary hypertension and GMO (reviews and original articles) were considered for the following arrangement of the results.

\section{A) The blood pressure regulating systems and their role in hypertension - possible targets and their clinical relevance}

I) The vegetative nervous system

1 . Heart $\beta$-1-adrenergic receptors ( $\beta$-1 AR), respectively adrenoreceptor kinases (ARK), heart M 2-receptors, atrial natriuretic peptide (ANP)

2 . Vascular adrenoreceptors: $\alpha$-adrenoreceptors $(\alpha-\mathrm{AR})$, $\alpha$-2-adrenoreceptors ( $\alpha$-2 AR)

3. Renal adrenoreceptors: renal $\beta$-2-adrenoreceptors $(\beta-2$ AR).

II) The vascular endothelium

1. Prostanoids, cyclooxygenases (COX), receptor subtype EP2 for prostaglandin E2 (PGE2 EP2)

2. Nitric oxide (NO), endothelial NO synthase (eNOS)

3. Peptides: natriuretic peptide (NP), atrial natriuretic peptide (ANP), brain natriuretic peptide (BNP) and C-type natriuretic peptide (CNP); NP-receptors and neutral endopeptidase (NEP); angiotensin II (ANG II); endothelin (ET-1), endothelin-1 receptors (ET-A and ET-B), endothelin converting enzyme (ECE); urotensin II (U II); endothelium-derived hyperpolarising factor (EDHF).

III) The Renin-Angiotensin-System (RAS)

1. Renin

2. Renin-Angiotensin-System (RAS), angiotensin converting enzyme (ACE), angiotensin converting enzyme 2 (ACE2), angiotensin II-receptor 1 (AT1), angiotensin IIreceptor 2 (AT2).

IV) Other targets

Angiotensin IV (Ang IV), adrenomedullin, asymmetric dimethylarginine (ADMA), hemoxygenase 1 (HO-1), regulator of $G$ protein signaling 2 (RGS 2), chromogranin (CHGA), vasodilatatory neuropeptides as calcitonin generelated peptide (CGRP) und substance $\mathrm{P}(\mathrm{SP})$, telomerase, neuropeptide Y receptor Y1 (NPY Y1), vascular $\mathrm{Na}^{+} / \mathrm{Ca}^{+}$ exchanger type 1 (NCX1), $\mathrm{Na}^{+} / \mathrm{K}^{+}$ATPase, reactive oxygen species (ROS), dopamine receptors, peroxisome proliferator activated receptor gamma (PPARgamma), PI3K gamma phosphoinositide-3 kinase gamma (PI3Kgamma), kallikrein kinin system (KKS), connexin, nonphagocytical NADPH oxidase, adenosine receptors, superoxide dismutase (SOD), RhoA/Rho-kinase (ROCK), bone morphogenic protein 4 (BMP4), cytochrome P450 (CYP450)/ lipoxygenase (LOX), tachykinine.

A detailed discussion of all publications found using these search terms would exceed the scope of this publication. In the complete study, further physiologically relevant connections to the various search terms are described in detail. A copy of the complete study may be requested from the Fund for Animal-free Research in Zurich, Switzerland.
In summary, none of the publications gave indications for new therapeutic approaches to the treatment of hypertension. Many of the physiological receptors and substances named under A I-IV still have no clinical relevance for the treatment of primary hypertension, i.e. ARK (Davidson and Koch, 2001; Koch, 2002; Petrofski and Koch, 2003; Keys and Koch, 2004; Hata et al., 2004; Hansen et al., 2006; Metaye et al., 2005 and 2006), PGE2 EP2 (Ushikubi et al., 2000; Breyer MD, 2000; Breyer et al., 2000), iNOS (Zhang et al., 2007; Kamanaka et al., 2003; Shen et al., 2003; Perdicakis et al., 2005), ACE2 (Der Sarkissian et al., 2006), AT-2 (Li et al., 2007), Angiotensin IV (Vauquelin et al., 2002; Banegas et al., 2006), adrenomedullin (Beltowski and Jamroz, 2004; Shimosawa und Fujita, 2005; Garcia et al., 2006), ADMA/DDAH (Cooke, 2005), Bach1 (Ozono, 2006), RGS2 (Le and Coffman, 2003; Tang et al., 2003; Doggrell, 2004; Semplicini et al., 2006), CHGA (Kim and Loh, 2005; Rao et al., 2007), CGRP and SP (Watson et al., 2002; Deng and Li, 2005, Marquez-Rodas et al., 2006), telomerase (Serrano and Andres, 2004), NPY Y1 (Pedrazzini, 2004), NCX1 (Iwamoto, 2006), dopamine receptors (O'Connell and Aherne, 2000; Yang et al., 2004; Zeng et al., 2004; Zeng et al., 2006), PPAR-gamma (Halabi and Sigmund, 2005; Touyz and Schiffrin, 2006), ROS (Wilcox, 2005; Touyz, 2004; Suzuki et al., 2006), PI3Kgamma (Oudit et al., 2004; Hirsch et al., 2006), KKS (Katori and Majima, 2003; Marcondes and Antunes, 2005; Chao and Chao, 2005; Chao et al., 2006), connexins (Haefliger et al., 2004), NADPH oxidase (Landmesser et al., 2002, Cogolludo et al., 2005), adenosine receptor (Funakoshi et al., 2006), SOD (Wilcox, 2006), BMP4 (Miriyala et al., 2006), CYP450/LOX (Immig 2006, Imming et al., 2007), tachykinine (Walsh and McWilliams; 2006).

For other known targets there are no indications of new therapeutic strategies e.g., $\alpha$-AR (Kable et al., 2000; Kanagy, 2005; O'Connell et al., 2006), $\beta$-2 AR (Bray and Boerwinkle, 2000; Guimaraes and Moura, 2001; Queen and Ferro, 2006), COX (Imming et al., 2007), NP (Melo et al., 2000; Schillinger et al., 2005), NEP (Mukkaddam-Daher, 2006), ET-1 (Kohan, 2006; Bolli et al., 2004; Cheng et al., 2004; Muller et al., 2003), AT-1 (Nickenig et al., 2006), HO-1 (Wu et al., 2005).

Further, the clinical relevance of already known target molecules could be confirmed in GMO models of hypertension e.g. NEP (Moro and Berlan, 2006), ET-1 (Chatziantoniou and Dussaule, 2000), ECE (Davenport and Maguire, 2006), renin (Muller and Luft, 2006), ACE (Niu et al., 2002), AT-1 (Crowley et al., 2004), adrenomedullin (Eto, 2001; Shimosawa et al., 2003), HO-1 (Agarwal and Nick, 2000; Hill-Kapturkzac et al., 2002; Chen, 2003; Perrella and Yet, 2003; Nascimiento-Silva et al., 2005; Deshane et al., 2005; Kirkby and Adin, 2006), $\mathrm{Na}^{+} / \mathrm{K}^{+}$ATPase (Blaustein et al., 2006), ROCK (Cogolludo et al., 2005). In other cases the clinical relevance in humans couldn't be confirmed in such animal models of hypertension e.g., COX (Harris et al., 2004; Mullins et al., 2006; Opay et al., 2006), Urotensin II (Zhu et al., 2006).

\section{B) General overview of animal models for human hypertension}

Of 19 reviews describing animal models of hypertension, 11 reviews (58\%) listed animal models for cardiovascular diseases. Among these were knock out and transgenic models for the 
well-known blood pressure regulating systems; however, the meaning of these animal models for the development of a therapy against the human disease was only speculative in terms like "might be a promising model for the future" or "requires further research" or similar phrases (Audoloy et al., 2000; Bader et al., 2000; Lake-Bruse and Sigmund, 2000; Fukamizu, 2000; Cvetkovic and Sigmund, 2000; Yagil and Yagil, 2001; Sugiyama et al., 2001; Lavoie et al., 2004; Barbosa et al., 2005; Lerman et al., 2005; McBride et al., 2006).

The remaining 8 reviews (42\%) were more critical and emphasised the limitations of the animal models when used to try to understand and treat human hypertension (Kurihara, 2001; Mullins and Mullins, 2003; Takahashi and Smithies, 2004; Herrera and Ruiz-Opazo, 2005; Smithies, 2005; Bernstein et al., 2005; Mullins et al., 2006).

Table 2 provides an overview of all the reviews that describe animal models for hypertension and shows the citation index as a measure of the citation frequency. $58 \%$ of the reviews were cited on average 0.7 times per year; $42 \%$ of the reviews 1.9 times per year.

Furthermore, it becomes obvious that reviews which deal with applied research or at least make sensible suggestions regarding the improvement of research, are cited on average more often than the other reviews. This is different from other literature searches, where basic research is usually cited more often (see for instance: Lindl et al., 2005).

The retrieved abstracts of original publications (except reviews) described animal models for hypertension (Denton et al., 2006; Tesson et al., 2005; Kapoor and Dikshit, 2005), but contained no indications of new therapies for hypertension. A further, more recent search of PubMed for all articles from 2007 until April 2008 also did not show any clinically relevant publications.

\section{C) Therapeutic approaches for human hypertension}

The clinical relevance of GMO was summarised in 2003 by Zambrowicz and Sands. The review describes the well-established targets ACE and AT-1 receptor as if they had been discovered recently in experiments with GMO. However, the clinical relevance of the drugs that were already known was merely confirmed by those experiments.
In 2007, Israili and colleagues suggested that hypertensive patients should first change their lifestyle before submitting to treatment or should at least support their therapy by reducing their risk factors (obesity, excessive salt and fat intake, low potassium diet, lack of physical exercise, excessive alcohol consumption). The new antihypertensive drugs include beta blockers, renin inhibitors, endothelin receptor antagonists, endopeptidase inhibitors - which have already been mentioned in this review, and aldosterone receptor blockers like spironolactone and epleron (Israili et al., 2007). The antihypertensive effects of these mineralocorticoid receptor blockers were discovered long before genetic manipulation (Sturtevant, 1958), though their use is limited by undesirable side effects. Clinical studies with epleron, a new, selective aldosterone receptor antagonist, appear promising (Sierra and Ruilope, 2004).

Based on the positive effects of combination therapy of antihypertensive medications, such as statins and lipid lowering drugs, e.g. calcium channel blockers (Escames et al., 2004; Martin-Ventura et al., 2006), the introduction of a "single pill" was suggested (Cogolludo et al., 2005; Blank et al., 2007).

Preclinical studies with a triple vasopeptidase inhibitor, CGS 35601, which may represent a new antihypertensive drug, have already been performed (Battistini et al., 2006). By inhibiting $\mathrm{ACE}$ and ECE, the production of the two strong vasoconstrictor peptides angiotensin II and endothelin is prevented. Furthermore, NEP is inhibited, and thus the degradation of the vasodilatory peptides, such as bradykinin, natriuretic peptides and adrenomedullin, is prevented. However, the idea to inhibit these target molecules did not arise from transgenic or knock-out animal experiments.

Despite positive findings in preclinical studies, gene therapy has not yet gained clinical relevance for the treatment of hypertension (Gelband et al., 2000; Phillips, 2000; Phillips et al., 2000; Khurana et al., 2001; Phillips, 2001; Baker, 2002; Hirooka et al., 2003; Veerasingham et al., 2004; Melo et al., 2004). The analysed publications mention or describe the use of vectors for therapeutic gene transfer that are already in clinical use. These were some small clinical studies for other cardiovascular diseases that had already been completed (Abraham et al., 2007; Quarck and Holvoet, 2004). However, these experiments were not designed carefully enough and are thus without further meaning for future gene therapy (see below). With regard to hy-

Tab. 2: Summary of the reviews describing animal models of hypertension with citation number and citation index*

\begin{tabular}{llllll}
\hline $\begin{array}{l}\text { Reviews } \\
\mathrm{n}=19\end{array}$ & $\begin{array}{l}\text { Mean } \\
\text { citation } \\
\text { index }\end{array}$ & $\begin{array}{l}\text { Citation index } \\
\text { (no citations) }\end{array}$ & $\begin{array}{l}\text { Citation index } \\
0.1-0.7 \\
\text { (1 to } 5 \text { citations) }\end{array}$ & $\begin{array}{l}\text { Citation index } \\
0.8-1.4 \\
(6 \text { to } 10 \text { citations) }\end{array}$ & $\begin{array}{l}\text { Citation index more than 1.4 } \\
\text { (more than 10 citations }\end{array}$ \\
\hline $\begin{array}{l}\text { mainly basic research } \\
n=11\end{array}$ & 0.7 & 5 & 2 & 1 & 3 \\
\hline $\begin{array}{l}\text { Mainly applied research } \\
n=8\end{array}$ & 1.9 & 3 & 1 & 1 & 4 \\
\hline
\end{tabular}

\footnotetext{
* The index was calculated as the number of citations divided by the time between year of publication (up to 2000) and 2007. The results were divided into 4 categories from citation index 0 ( 0 citation in maximal 7 years) to more than 1.4 (10 citations in maximal 7 years). At least one citation per year is required to achieve a citation index of 1 .
} 
pertension, no clinical studies for any kind of antihypertensive gene therapy have been reported (Melo et al., 2005). The authors of these review claimed that gene therapy for hypertension would be simple and safe. However, it is clear that all these vectors are still not safe enough to be used in humans: cytotoxicity is a risk factor for all vectors and, in addition, cancer and mutations are risks for all viral vectors (Raizada and Der Sarkissian, 2005; Heistad, 2006). Gene therapy via gene transfer using viral or nonviral vectors has only been performed in animal experiments to date (Simonson et al., 2005; Nakamura et al., 2006). With regard to primary hypertension, such approaches still have no discernable clinical impact (Puddu, 2006). Other therapies, such as RNAi or stem cell therapy, are still at the stage of basic research (Melo et al., 2005; Nordlie et al., 2006).

Furthermore, it has been suggested that genetic polymorphisms should be considered in future when deciding on a therapeutic strategy (Siest et al., 2004), although the meaning of polymorphisms for hypertension remains "small and clinically irrelevant" (Rosskopf et al., 2007).

\section{D) Suggestions for the therapy of sequelae of human hypertension}

In animal models, certain targets, such as ARK, endothelin or adrenomedullin, had a positive influence on organ damage resulting from hypertension; however, respective gene therapies are not yet applied in humans.

In connection with cardiac insufficiency - one of the consequences of chronic hypertension - gene therapy led to a reduction of cardiac hypertrophy in animal models (Pleger et al., 2005), but has not yet gained clinical relevance for human therapy.

Furthermore, well-known drugs, such as aliskiren (renin inhibitor, Pilz et al., 2005), imatinib (drug using to treat leukaemia, Schellings et al., 2006), angiotensin II receptor blocker (Yasunari et al., 2005) as well as lipid lowering drugs (e.g., fibrate, Muller et al., 2004), reduce organ damage in animal models.

The antioxidant tetrahydrobiopterin $\mathrm{BH} 4$, a cofactor of eNOS, has been suggested as a therapy for the consequences of hypertension on the heart (Takimoto et al., 2005; Moens and Kass, 2006). Although oxidative stress (i.e. ROS) seems to be associated with hypertension, therapeutic approaches using antioxidants have been disappointing (Wilcox, 2006).

Regenerative stem cell therapy has been suggested as another promising therapeutic approach to treat the effects of hypertension on the endothelium (Wang et al., 2005). This would involve using endothelial stem cells from bone marrow, which are already in clinical trials (Dong and Goldschmidt-Clermont, 2007). However, regenerative stem cell therapy is entirely unrelated to GMO experiments.

Indications for gene therapy for other cardiovascular diseases have been found, e.g. clinical studies with antisense oligonucleotides against artherosclerosis ("E2F decoy" currently in Phase II/III clinical trials, Aboul-Fadl, 2005), as well as gene therapy based on adenoviral and plasmid-mediated VEGF gene transfer as a therapy for arteriosclerotic cardiovascular diseases (Freedman, 2002; Malecki, 2005). Large clinical studies with gene therapeutic approaches for the sequelae of hypertension ("an- giogenetic gene therapy") however did not show the expected positive results observed in small clinical studies and animal experiments (Khurana et al., 2005; Nordlie et al., 2006).

\section{E) Suggestions to improve cardiovascular research}

Despite intensive research, the validation of new therapeutic target molecules is progressing slowly; a target molecule can be validated by developing a drug that selectively interacts with the target molecule and shows clinical effectiveness (Williams, 2003). Many publications contain suggestions or speculations to improve drug development.

Species differences, as well as compensatory mechanisms which attempt to normalise blood pressure despite genetic modification designed to achieve hypertension, complicate the interpretation of results from GMO experiments (Kurihara, 2001; Mullins and Mullins, 2002; Mullins et al., 2006). The increased use of computer simulations could be helpful, as the elucidation of the paradoxical results of gene titration experiments with the ACE gene have proven (Smithies, 2005). Therefore, Moore suggested systems biology for the detection, characterisation and interpretation of gene-gene interactions (Moore et al., 2006).

With regard to GMO studies, standardisation of the animal experiments is recommended, as the handling and housing of laboratory animals has been shown to have considerable influence on biological variables (Champy et al., 2004). Further, some researchers argue for a stronger focus on clinical research, as cellular and animal models cannot sufficiently model the human disease (e.g. Lindsay, 2005). Reference is made to the importance of heterozygotes of knock-out animals. These animals show the effects of quantitative expression of the gene in question. When genetic variation in the gene leads to hypertension both in heterozygous and homozygous animals, this can indicate a role of respective polymorphisms in humans (Takahashi and Smithies, 2004).

The elucidation of the effects of natural antihypertensives on the molecular level could also lead to improvements in the drug development process. One review investigated the antihypertensive effects of red wine. The activation of eNOS appears to play a decisive role (Leighton et al., 2006). Further, the effects of natural antihypertensive substances, such as linseed (Omoni and Aluko, 2006) or ginseng root (Liu et al., 2006), as well as acupuncture (Kim et al., 2006), have been investigated in animal experiments on the molecular level. Liu explored the antihypertensive effects of resveratrol, a phytoestrogen from grapes. In this case, the inhibition of ET-1 expression appears to play a role (Liu et al., 2003).

\section{Discussion}

Transgenic and knock-out mouse models for hypertension have existed since 1990 (Kurihara, 2001). Until 2001, it was believed that the results from animal experiments could be extrapolated relatively quickly to humans, despite speciesspecific differences. However, five years later, researchers became more careful with their interpretations. According to the newer publications, it is not always clear whether blood 
pressure changes in GMO are a direct or indirect consequence of the genetic manipulation.

The extrapolation from animal experiments to humans must be considered in the meantime with much more caution. Today, it can no longer be assumed that every gene that plays a role in hypertension in an animal is also relevant in humans. As a multifactorial disease, hypertension can be the result of many small increments of blood pressure resulting from various genetic and environmental changes. Genetic predisposition and physiological adaptation to the environment can contribute equally. A simple, monogenic cause is clearly excluded. It appears that many small genetic modifications make contributions that are not problematic in isolation, but lead to increased blood pressure when combined (Mullins et al., 2006). Such multifactorial causation becomes clear in clinical studies with known antihypertensive drugs, such as ACE inhibitors, beta blockers and calcium channel blockers. Beside decreased blood pressure, other effects are observed that cannot be attributed solely to drug effects (Sever et al., 2006).

In the opinion of many researchers, a targeted genetic modification is a starting point for the identification of interactions that lead to hypertension, although the resulting phenotypes of GMO are still complicated. According to Mullins and colleagues (2006), the homeostasis of the blood pressure is under polygenetic control, so that the body can overcome the effects of every mutation by complementary mechanisms that normalise the blood pressure. The genetic complexity of each individual provides the ability to adapt to such changes, or to environmental alterations. Why should this be different in GMO?

From the perspective of the present evidence, some other questions remain unanswered:

To what degree do animal and human physiologies correlate with respect to blood pressure and its regulation? What relevance do the knock-out or transgenic phenotypes have? Do complementary regulatory mechanisms prevent the identification of the true function of knock-out or overexpressed genes? To what degree can mouse genetics aid in the development of new human therapies and the search for new target molecules?

\section{Conclusions}

The intention of the transgenic and knock-out approach in hypertension has always been to make an important contribution to cardiovascular research and thus provide indications for new therapeutic approaches. This is apparent from the motivations of the different research approaches stated in most of the publications examined.

However, it has become clear in the course of this investigation that the publications dealing with basic research have not yet provided any indications for possible applications of the results and have provided no basis for human diagnostic or therapeutic application. The abstracts of the publications dealing with applied research contained some indications of possible applications of the results for therapeutic purposes, but no concrete therapeutic procedures. The potential human benefit in such cases remains speculative. None of the publications examined contained indications of direct applications of results gained by using GMO, whether in humans or animals. These results were expected given the complexity of hypertension, as we have hardly begun to understand its genetic causes and have no means of controlling the environmental influences that interact with such genetic factors.

\section{References}

Aboul-Fadl, T. (2005). Antisense oligonucleotides: the state of the art. Curr. Med. Chem. 12, 2193-2214.

Abraham, N. G., Asija, A., Drummond, G., Peterson, S. (2007). Heme oxygenase-1 gene therapy: Recent advances and therapeutic applications. Curr. Gene Ther. 7, 89-108.

Agarwal, A. and Nick, H. S. (2000). Renal response to tissue injury: lessons from heme oxygenase-1 Gene ablation and expression. J. Am. Soc. Nephrol. 11, 965-973.

Agarwal, A., Williams, G. H. and Fisher, N. D. L. (2005). Genetics of human hypertension. Trends in Endocronolgy and Metabolism 16, 127-133.

Audoloy, L. P., Le, T. H. and Coffman, T. M. (2000). What can knockout mice contribute to an understanding of hypertension? Curr. Hypertens. Rep. 2, 192-197.

Bader, M., Bohnemeier, H., Zollmann, F. S. et al. (2000).Transgenic animals in cardiovascular disease research. Exp. Physiology 85, 713-731.

Banegas, I., Prieto, I., Vives, F. et al. (2006). Brain aminopeptidases and hypertension. J. Renin Angiotensin Aldosterone Syst. 7, 129-134.

Barbosa, M. E., Alenina, N. and Bader, M. (2005). Induction and analysis of cardiac hypertrophy in transgenic animal models. Methods Mol. Med. 112, 339-352.

Battistini, B., Berthiaume, N., Kelland, N. F. et al. (2006). Profile of past and current clinical trials involving endothelin receptor antagonists: the novel "-sentan" class of drug. Exp Biol. Med. 231, 653-695.

Beltowski, J., Jamroz, A. (2004). Adrenomedullin--what do we know 10 years since its discovery? Pol. J. Pharmacol. 56, 5-27.

Bernstein, K. E., Xiao, H. D., Adams, J. W. et al. (2005). Establishing the role of angiotensin-converting enzyme in renal function and blood pressure control through the analysis of genetically modified mice. J. Am. Soc. Nephrol. 16, 583-591.

Bernstein, K. E., Xiao, H. D., Frenzel, K. et al. (2005). Six truisms concerning $\mathrm{ACE}$ and the renin-angiotensin system educed from the genetic analysis of mice. Circ Res. 96, 11351144.

Blank, R., Hobbs, F. D., Zamorano, J. and Girerd, X. (2007). A single-pill combination of amlodipine besylate and atorvastatin calcium (update). Drugs Today 43, 157-177.

Blaustein, M. P., Zhang, J., Chen, L. and Hamilton, B. P. (2006). How does salt retention raise blood pressure? Am. J. Physiol. Regul. Integr. Comp. Physiol. 290, R 514-523.

Bolli, M. H., Marfurt, J., Grisostomi, C. et al. (2004). Novel benzo[1,4]diazepin-2-one derivatives as endothelin receptor antagonists. J. Med. Chem. 47, 2776-2795. 
Bray, M. S. and Boerwinkle, E. (2000). The role of beta(2)adrenergic receptor variation in human hypertension. Curr. Hypertens. Rep. 2, 39-43.

Breyer, M. D. and Breyer, R. M. (2000). Prostaglandin E receptors and the kidney. Am. J. Physiol. Renal Physiol. 279, F12-23.

Breyer, M. D. and Breyer, R. M. (2000). Prostaglandin receptors: their role in regulating renal function. Curr. Opin. Nephrol. Hypertens. 9, 23-29.

Breyer, R. M., Kennedy, C. R., Zhang, Y. and Breyer, M. D. (2000). Structure-function analyses of eicosanoid receptors. Physiologic and therapeutic implications. Ann. N. Y. Acad. Sci. 905, 221-231.

Champy, M. F., Selloum, M., Piard, L. et al. (2004). Mouse functional genomics requires standardization of mouse handling and housing conditions. Mamm. Genome 15, 768-783.

Chao, J., Bledsoe, G., Yin, H. and Chao, L. (2006). The tissue kallikrein-kinin system protects against cardiovascular and renal diseases and ischemic stroke independently of blood pressure reduction. J. Biol. Chem. 387, 665-675.

Chao, J. and Chao, L. (2005). Kallikrein-kinin in stroke, cardiovascular and renal disease. Exp. Physiol. 90, 291-298.

Chatziantoniou, C. and Dussaule, J. C. (2000). Endothelin and renal vascular fibrosis: of mice and men. Curr. Opin. Nephrol. Hypertens. 9, 31-36.

Chen, Y. H., Yet, S. F. and Perrella, M. A. (2003). Role of heme oxygenase-1 in the regulation of blood pressure and cardiac function. Exp. Biol. Med. 228, 447-453.

Cheng, M. F. and Fang, J. M. (2004). Liquid-phase combinatorial synthesis of 1,4-benzodiazepine-2,5-diones as the candidates of endothelin receptor antagonism. J. Comb. Chem. 6, 99-104.

Cogolludo, A., Perez-Vizcaino, F. and Tamargo, J. (2005). New insights in the pharmacological therapy of arterial hypertension. Curr. Opin. Nephrol. Hypertens. 14, 423-427.

Cooke, J. P. (2005). ADMA: its role in vascular disease. Vasc. Med. 10 (Suppl. 1), S11-17.

Crowley, S. D., Tharaux, P. L., Audoly, L. P. and Coffman, T. M. (2004). Exploring type I angiotensin (AT1) receptor functions through gene targeting. Acta Physio.l Scand. 181, 561-570.

Cogolludo, A., Perez-Vizcaino, F. and Tamargo, J. (2005). New insights in the pharmacological therapy of arterial hypertension. Curr. Opin. Nephrol. Hypertension 14, 423-427.

Cvetkovic, B. and Sigmund, C. D. (2000). Understanding hypertension through genetic manipulation in mice. Kidney Int 57, 863-874.

Davenport, A. P. and Maguire, J. J. (2006). Endothelin. Handb. Exp. Pharmacol. 176, 295-329.

Davidson, M. J. and Koch, W. J. (2001). Genetic manipulation of beta-adrenergic signalling in heart failure. Acta Physiol. Scand. 173, 145-150.

Denton, K. M., Kett, M. M. and Dodic M. (2006). Programming hypertension - Animal models: causes and mechanisms. Adv. in Exp. Med. Biol. 573, 103-120.

Deng, P. Y. and Li, Y. J. (2005). Calcitonin gene-related peptide and hypertension. Peptides 26, 1676-1685.
Der Sarkissian, S., Huentelman, M. J., Stewart, J. et al. (2006). ACE2: A novel therapeutic target for cardiovascular diseases. Prog. Biophys. Mol. Biol. 91, 163-198.

Deshane, J., Wright, M. and Agarwal, A. (2005). Heme oxygenase-1 expression in disease states. Acta Biochim. Pol. 52, 273-284.

Doggrell, S. A. (2004). Is RGS-2 a new drug development target in cardiovascular disease? Expert Opin. Ther. Targets. 8, 355-358.

Dong, C. and Goldschmidt-Clermont, P. J. (2007). Endothelial progenitor cells: a promising therapeutic alternative for cardiovascular disease. J. Interv. Cardiol. 20, 93-99.

Escames, G., Khaldy, H., Leon, J. et al. (2004).Changes in iNOS activity, oxidative stress and melatonin levels in hypertensive patients treated with lacidipine. J. Hypertens. 22, 629-635.

Freedman, S. B. (2002). Clinical trials of gene therapy for atherosclerotic cardiovascular disease. Curr. Opin. Lipidol. 13, 653-661.

Fukamizu,A. (2000). Genomic expression systems on hierarchy and network leading to hypertension: long on history, short on facts. Hypertension Res. 23, 545-552.

Funakoshi, H., Chan, T. O., Good, J. C. et al. (2006). Regulated overexpression of the A1-adenosine receptor in mice results in adverse but reversible changes in cardiac morphology and function. Circulation 114, 2240-2250.

Garcia, M. A., Martin-Santamaria, S., de Pascual-Teresa, B. et al. (2006). Adrenomedullin: a new and promising target for drug discovery. Expert Opin. Ther. Targets 10, 303-317.

Gelband, C. H., Katovich, M. J. and Raizada, M. K. (2000). Current perspectives on the use of gene therapy for hypertension. Circ. Res. 87, 1118-1122.

Guimaraes, S. and Moura, D. (2001). Vascular adrenoceptors: an update. Pharmacol. Rev. 53, 319-356.

Haefliger, J. A., Nicod, P. and Meda, P. (2004). Contribution of connexins to the function of the vascular wall. Cardiovasc. Res. 62, 345-56.

Halabi, C. M. and Sigmund, C. D. (2005). Peroxisome proliferator-activated receptor-gamma and its agonists in hypertension and atherosclerosis: mechanisms and clinical implications. Am. J. Cardiovasc. Drugs 5, 389-398.

Hansen, J. L., Theilade, J., Aplin, M. and Sheikh, S. P. (2006). Role of G-protein-coupled receptor kinase 2 in the heart. Do regulatory mechanisms open novel therapeutic perspectives? Trends Cardiovasc. Med. 16, 169-177.

Harris, R. C., Zhang, M. Z. and Cheng, H. F. (2004). Cyclooxygenase- 2 and the renal renin-angiotensin system. Acta Physiol. Scand. 181, 543-547.

Hata, J. A., Williams, M. L. and Koch, W. J. (2004). Genetic manipulation of myocardial beta-adrenergic receptor activation and desensitization. J. Mol. Cell Cardiol. 37, 11-21.

Herrera, V. L. and Ruiz-Opazo, N. (2005). Genetic studies in rat models: insights into cardiovascular disease. Curr. Opin. Lipidol. 16, 179-191.

Heistad, D. D. (2006). Gene therapy for vascular disease. Vascul. Pharmacol. 45, 331-333.

Hill-Kapturczak, N., Chang, S. H. and Agarwal, A. (2002). 
Heme oxygenase and the kidney. DNA Cell Biol. 21, 307321.

Hirooka, Y., Kishi, T., Sakai, K. et al. (2003). Effect of overproduction of nitric oxide in the brain stem on the cardiovascular response in conscious rats. J. Cardiovasc. Pharmacol. 41, S119-126.

Hirsch, E., Lembo, G., Montrucchio, G. et al. (2006). Signaling through PI3Kgamma: a common platform for leukocyte, platelet and cardiovascular stress sensing. Thromb. Haemost. 95, 29-35.

Imig, J. D. (2006). Eicosanoids and renal vascular function in diseases. Clin. Sci. (Lond) 111, 21-34.

Imming, P., Sinning, C. and Meyer, A. (2007). Drugs, their targets and the nature and number of drug targets. Nat. Rev. Drug Discov. 5, 821-34.

Israili, Z. H., Hernandez-Hernandez, R. and Valasco, M. (2007). The future of antihypertensive treatment. Am. J. Ther. 14, 121-134.

Iwamoto, T. (2006). Vascular $\mathrm{Na}^{+} / \mathrm{Ca}^{+}$exchanger: implications for the pathogenesis and therapy of salt-dependent hypertension. Am. J. Physiol. Regul. Integr. Comp. Physiol. 290, R 536-545.

Kable, J. W., Murrin, L. C. and Bylund, D. B. (2000). In vivo gene modification elucidates subtype-specific functions of alpha(2)-adrenergic receptors. J. Pharmacol. Exp. Ther. 293, 1-7.

Kamanaka, Y., Kawabata, A., Matsuya, H. et al. (2003). Effect of a potent iNOS inhibitor (ONO-1714) on acetaminopheninduced hepatotoxicity in the rat. Life Sci. 74, 793-802.

Kanagy, N. L. (2005). Alpha(2)-adrenergic receptor signalling in hypertension. Clin. Sci. (Lond) 109, 431-437.

Kapoor, K. and Dikshit, M. (2005). Transgenic and gene-knockout rodents as research tools for cardiovascular disordersScand. J. Lab. Animal Sc. 32, 49-67.

Katori, M. and Majima, M. (2003). The renal kallikrein-kinin system: its role as a safety valve for excess sodium intake, and its attenuation as a possible etiologic factor in salt-sensitive hypertension. Crit. Rev. Clin. Lab. Sci. 40, 43-115.

Keys, J. R. and Koc,h W. J. (2004). The adrenergic pathway and heart failure. Recent Prog. Horm. Res. 59, 13-30.

Khurana, R., Martin, J. F., Zachary, I. (2001). Gene therapy for cardiovascular disease: a case for cautious optimism. Hypertension 38, 1210-1216.

Khurana, R., Simons, M., Martin, J. F. and Zachary, I. C. (2005). Role of angiogenesis in cardiovascular disease: a critical appraisal. Circulation 112, 1813-1824.

Kim, D. D., Pica, A. M., Duran, R. G. and Duran, W. N. (2006). Acupuncture reduces experimental renovascular hypertension through mechanisms involving nitric oxide synthases. Microcirculation.13, 577-585.

Kim, T., Loh, Y. P. (2005). Chromogranin A: a surprising link between granule biogenesis and hypertension. J. Clin. Invest. 115, 1711-1713.

Kirkby, K. A. and Adin, C. A. (2006). Products of heme oxygenase and their potential therapeutic applications. Am. J. Physiol.Renal. Physiol. 290, F 563-571.
Koch, W. J. (2002). Gene transfer of beta-adrenergic signaling components for heart failure. J. Card. Fail. 8, S 526-531.

Kohan, D. E. (2006). The renal medullary endothelin system in control of sodium and water excretion and systemic blood pressure. Curr. Opin. Nephrol. Hypertens. 15, 34-40.

Kurihara, H. (2001). Symposium on the etiology of hypertension - summarizing studies in 20th century. 2. Genetic engineering in hypertension research. Intern. Med.40, 147-151.

Landmesser, U., Cai, H., Dikalov, S. et al. (2002). Role of p47(phox) in vascular oxidative stress and hypertension caused by angiotensin II. Hypertension 40, 511-515.

Lake-Bruse, K. D. and Sigmund, C. D. (2000). Transgenic and knockout mice to study the renin-angiotensin system and other interacting vasoactive pathways. Curr. Hypertens. Rep. 2, 211-216.

Lavoie, J. L., Bianco, R. A., Sakai, K. et al. (2004). Transgenic mice for studies of the renin-angiotensin system in hypertension. Acta Physiol. Scand. 181, 571-577.

Le, T. H. and Coffman, T. M. (2003). RGS2: a „turn-off“ in hypertension. J. Clin. Invest. 111, 441-443.

Leighton, F., Miranda-Rottmann, S. and Urquiaga, I. (2006). A central role of eNOS in the protective effect of wine against metabolic syndrome. Cell. Biochem. Funct. 24, 291-298.

Lerman, L. O., Chade, A. R., Sica, V. and Napoli, C. (2005). Animal models of hypertension: an overview. J. Lab. Clin. Med. 146, 160-173.

Li, H., Gao, Y., Grobe, J. L. et al. (2007). Potentiation of the antihypertensive action of losartan by peripheral overexpression of the ANG II type 2 receptor. Am. J. Physiol. Heart Circ. Physiol. 292, H727-735.

Lindl, T., Völkel, M. and Kolar, R. (2005). Tierversuche in der biomedizinischen Forschung. ALTEX 22, 143-151.

Lindsay, M. A. (2005). Finding new drug targets in the 21 st century. Drug Discovery Today 10, 1683-1687.

Liu, K. L., Chen, H. W., Wang, R. Y. et al. (2006). DATS reduces LPS-induced iNOS expression, NO production, oxidative stress, and NF-kappaB activation in RAW 264.7 macrophages. J. Agric. Food Chem. 54, 3472-3478.

Liu, J. C., Chen, J. J., Chan, P. et al. (2003). Inhibition of cyclic strain-induced endothelin-1 gene expression by resveratrol. Hypertension 42, 1198-1205.

Malecki, M., Kolsut, P. and Proczka, R. (2005). Angiogenic and antiangiogenic gene therapy. Gene Ther. 12, S159-169.

Marcondes, S. and Antunes, E. (2005). The plasma and tissue kininogen-kallikrein-kinin system: role in the cardiovascular system. Curr. Med. Chem. Cardiovasc. Hematol. Agents. 3, 33-44.

Marquez-Rodas, I., Longo, F., Rothlin, R. P. and Balfagon, G. (2006). Pathophysiology and therapeutic possibilities of calcitonin gene-related peptide in hypertension. J. Physiol. Biochem. 62, 45-56.

Marteau, J. B., Zaiou, M., Siest, G. and Visvikis-Siest, S. (2005). Genetic determinants of blood pressure regulation. J. Hypertens. 23, 2127-43.

Martin-Ventura, J. L., Tunon, J., Duran, M. C. et al . (2006). Vascular protection of dual therapy (atorvastatin-amlodipine) in 
hypertensive patients. J. Am. Soc. Nephrol. 17, S189-193.

McBride, M. W., Graham, D., Delles, C. and Dominiczak, A. F. (2006). Functional genomics in hypertension. Curr. Opin. Nephrol. Hypertens. 15, 145-151.

Melo, L. G., Gnecchi, M., Pachori, A. S. et al. (2004). Endothelium-targeted gene and cell-based therapies for cardiovascular disease. Arterioscler. Thromb. Vasc. Biol. 24, 1761-1774.

Melo, L. G., Pachori, A. S., Gnecchi, M. and Dzau, V. J. (2005). Genetic therapies for cardiovascular diseases. Trends Mol. Med. 11, 240-250.

Melo, L. G., Steinhelper, M. E., Pang, S. C. et al. (2000). ANP in regulation of arterial pressure and fluid-electrolyte balance: lessons from genetic mouse models. Physiol. Genomics 29, 45-58.

Metaye, T., Gibelin, H., Perdrisot, R. and Kraimps, J. L. (2005). Pathophysiological roles of G-protein-coupled receptor kinases. Cell Signal. 17, 917-28.

Metaye, T., Perdrisot, R., Kraimps, J. L. (2006). GRKs and arrestins: the therapeutic pathway? Med. Sci. (Paris) 22, 53743.

Miriyala, S., Gongora Nieto, M. C., Mingone, C. et al. (2006). Bone morphogenic protein-4 induces hypertension in mice: role of noggin, vascular NADPH oxidases, and impaired vasorelaxation. Circulation. 113, 2818-25.

Moens, A. L. and Kass, D. A. (2006). Tetrahydrobiopterin and cardiovascular disease. Arterioscler. Thromb. Vasc. Biol. 26, 2439-2444.

Moore, J. H., Gilbert, J. C., Tsai, C. T. et al. (2006). A flexible computational framework for detecting, characterizing, and interpreting statistical patterns of epistasis in genetic studies of human disease susceptibility. J. Theor. Biol. 241, 252-261.

Moro, C. and Berlan, M.(2006). Cardiovascular and metabolic effects of natriuretic peptides. Fundam. Clin. Pharmacol. 1, 41-49.

Muller, D. N., Fiebeler, A., Park, J. K. et al. (2003). Angiotensin II and endothelin induce inflammation and thereby promote hypertension-induced end-organ damage. Clin. Nephrol. 60, S 2-12.

Muller, D. N. and Luft, F. C. (2006). Direct renin inhibition with aliskiren in hypertension and target organ damage. Clinical Journal of the American Society of Nephrology 1, 221-228

Muller, D. N., Theuer, J., Shagdarsuren, E. et al. (2004). A peroxisome proliferator-activated receptor-alpha activator induces renal CYP2C23 activity and protects from angiotensin II-induced renal injury. Am. J. Pathol. 164, 521-532.

Mullins, L. J., Bailey, M. A. and Mullins, J. J. (2006). Hypertension, kidney, and transgenics: a fresh perspective. Physiol. Rev. 86, 709-746.

Mullins, L. J., Bailey, M. A. and Mullins, J. J. (2006). Hypertension, kidney, and transgenics: a fresh perspective. Physiol. Rev. 86, 709-746.

Mukaddam-Daher, S. (2006). Natriuretic peptides as therapeutic targets. Expert Opin. Ther. Targets. 10, 239-252.

Mullins, L. J. and Mullins, J. (2003). Current successes and limitations of using genetic modification for blood pressure research. Pflugers Arch. 445, 491-494.
Nakamura, Y., Kogure, K., Yamada, Y. et al. (2006). Significant and prolonged antisense effect of a multifunctional envelopetype nano device encapsulating antisense oligodeoxynucleotide. J. Pharm. Pharmacol. 58, 431-437.

Nascimento-Silva, V., Arruda, M. A., Barja-Fidalgo, C. et al. (2005). Novel lipid mediator aspirin-triggered lipoxin A4 induces heme oxygenase-1 in endothelial cells. Am. J. Physiol. Cell Physiol. 289, C 557-563.

Nickenig, G., Ostergren, J. and Struijker-Boudier, H. (2006). Clinical evidence for the cardiovascular benefits of angiotensin receptor blockers. J. Renin Angiotensin Aldosterone Syst. 7, S1-7.

Niu, T., Chen X. and Xu X. (2002). Angiotensin converting enzyme gene insertion/deletion polymorphism and cardiovascular disease: therapeutic implications. Drugs 62, 977-993.

Nordlie, M. A., Wold, L. E., Simkhovich, B. Z. et al. (2006). Molecular aspects of ischemic heart disease: ischemia/reperfusion-induced genetic changes and potential applications of gene and RNA interference therapy. J. Cardiovasc. Pharmacol. Ther. 11, 17-30.

O'Connell, D. P. and Aherne, A. M. (2000). Renal dopaminergic mechanisms and hypertension: a chronology of advances. Clin. Exp. Hypertens. 22, 217-249.

O'Connell, T. D., Swigart, P. M., Rodrigo, M. C. et al. (2006). Alpha1-adrenergic receptors prevent a maladaptive cardiac response to pressure overload. J. Clin. Invest. 116, 10051015.

Omoni, A. O. and Aluko, R. E. (2006). Effect of cationic flaxseed protein hydrolysate fractions on the in vitro structure and activity of calmodulin-dependent endothelial nitric oxide synthase. Mol. Nutr. Food Res. 50, 958-966.

Opay, A. L., Mouton, C. R., Mullins, J. J. and Mitchell, K. D. (2006). Cyclooxygenase-2 inhibition normalizes arterial blood pressure in CYP1A1-REN2 transgenic rats with inducible ANG II-dependent malignant hypertension. Am. J. Physiol. Renal Physiol. 291, F 612-618.

Oudit, G. Y., Sun, H., Kerfant, B. G. et al. (2004). The role of phosphoinositide-3 kinase and PTEN in cardiovascular physiology and disease. J. Mol. Cell Cardiol. 37, 449-471.

Ozono, R. (2004). New biotechnological methods to reduce oxidative stress in the cardiovascular system: focusing on the Bach1/heme oxygenase-1 pathway. Curr. Pharm. Biotechnol. 7, 87-93.

Pedrazzini, T. (2004). Importance of NPY Y1 receptor-mediated pathways: assessment using NPY Y1 receptor knockouts. Neuropeptides 38, 267-275.

Perdicakis, B., Montgomery, H. J., Abbott, G. L. et al. (2005). Photocontrol of nitric oxide production in cell culture using a caged isoform selective inhibitor. Bioorg. Med. Chem. 13, 47-57.

Perrella, M. A. and Yet, S. F. (2003). Role of heme oxygenase-1 in cardiovascular function. Curr. Pharm. Des. 9, 2479-2487.

Petrofski, J. A. and Koch, W. J. (2003). The beta-adrenergic receptor kinase in heart failure. J. Mol. Cell. Cardiol. 35, 11671174.

Phillips, M. I., Galli, S. M. and Mehta, J. L. (2000). The poten- 
tial role of antisense oligodeoxynucleotide therapy for cardiovascular disease. Drugs 60, 239-248.

Phillips, M. I. (2000). Somatic gene therapy for hypertension. Braz. J. Med. Biol. Res. 33, 715-721.

Phillips, M. I. (2001). Gene therapy for hypertension: the preclinical data. Hypertension 38, 543-548.

Pilz, B., Shagdarsuren, E., Wellner, M. et al. (2005). Aliskiren, a human renin inhibitor, ameliorates cardiac and renal damage in double-transgenic rats. Hypertension 46, 569-576.

Pleger, S. T., Remppis, A., Heidt, B. et al. (2005). S100A1 gene therapy preserves in vivo cardiac function after myocardial infarction. Mol. Ther. 12, 1120-1129.

Puddu, G. M. (2006). Gene-based therapy for hypertension: do preclinical data suggest a promising future? Cardiology 108 , 40-47.

Quarck, R. and Holvoet, P. (2004). Gene therapy approaches for cardiovascular diseases. Curr. Gene Ther. 4, 207-223.

Queen, L. R. and Ferro, A. (2006). Beta-adrenergic receptors and nitric oxide generation in the cardiovascular system. Cell Mol. Life Sci. 63, 1070-1083.

Raizada, M. K. and Der Sarkissian, S. (2006). Potential of gene therapy strategy for the treatment of hypertension. Hypertension 47, 6-9.

Rao, F., Wen, G., Gayen, J. R. et al. (2007). Catecholamine release-inhibitory peptide catestatin (chromogranin A(352372)): naturally occurring amino acid variant Gly364Ser causes profound changes in human autonomic activity and alters risk for hypertension. Circulation 115, 2271-2281.

Rang, H. P., Dale, M. M., Ritter, J. M. and Moore, P. K. (2003). Pharmacology, 5th Edition, Edinbourgh, London: Churchill Livingstone.

Rosskopf, D., Schurks, M., Rimmbach, C. and Schafers, R. (2007). Genetics of arterial hypertension and hypotension. Naunyn Schmiedebergs Arch. Pharmacol. 374, 429-469.

Schellings, M. W., Baumann, M., van Leeuwen, R. E. et al. (2006). Imatinib attenuates end-organ damage in hypertensive homozygous TGR(mRen2)27 rats. Hypertension 47, 467-474.

Schillinger, K. J., Tsai, S. Y., Taffet, G. E. et al. (2006). Regulatable atrial natriuretic peptide gene therapy for hypertension. Proc. Natl. Acad. Sci. USA. 102, 13789-13794.

Scott, B. B., McGeehan, G. M. and Harrison, R. K. (2006). Development of inhibitors of the aspartyl protease renin for the treatment of hypertension. Curr. Protein Pept. Sci. 7, 241254.

Semplicini, A., Lenzini, L., Sartori, M. et al. (2006). Reduced expression of regulator of G-protein signaling 2 (RGS2) in hypertensive patients increases calcium mobilization and ERK1/2 phosphorylation induced by angiotensin II. J. Hypertens. 24, 1115-1124.

Serrano, A. L. and Andres, V. (2004). Telomeres and cardiovascular disease: does size matter? Circ. Res. 94, 575-84.

Sever, P. S., Poulter, N. R., Elliott, W. J. et al. (2006). Blood pressure reduction is not the only determinant of outcome. Circulation 113, 2754-2774.

Shen, L. J., Lin, W. C., Beloussow, K. et al. (2003).Recombinant arginine deiminase as a differential modulator of inducible (iNOS) and endothelial (eNOS) nitric oxide synthetase activity in cultured endothelial cells. Biochem. Pharmacol. 66, 1945-1952.

Shimosawa, T. and Fujita, T. (2005). Adrenomedullin as a potent antioxidative and antiatherosclerotic substance. Drug News Perspect. 18, 185-189.

Shimosawa, T., Matsui, H., Xing, G. et al. (2003). Organ-protective effects of adrenomedullin. Hypertens. Res. 26, S109112.

Sierra, C. and Ruilope, L. M. (2004). Role of the selective aldosterone receptor blockers in arterial hypertension. J. Renin Angiotensin Aldosterone Syst. 5, 23-25.

Siest, G., Jeannesson, E., Berrahmoune, H. et al. (2004) Pharmacogenomics and drug response in cardiovascular disorders. Pharmacogenomics 5, 779-802.

Simonson, O. E., Svahn, M. G., Tornquist, E. et al. (2005). Bioplex technology: novel synthetic gene delivery pharmaceutical based on peptides anchored to nucleic acids. Curr. Pharm. Des. 11, 3671-3680.

Smithies, O. (2005). Many little things: one geneticist's view of complex diseases. Nat. Rev. Genet. 6, 419-425.

Sturtevant, F. M. (1958). Antihypertensive effects of an aldosterone antagonist. Science 127, 1393-1394.

Sugiyama, F., Yagami, K. and Paigen, B. (2001). Mouse models of blood pressure regulation and hypertension. Curr. Hypertens. Rep. 3, 41-48.

Suzuki, H., Frank, G. D., Utsunomiya, H. et al. (2006). Current understanding of the mechanism and role of ROS in angiotensin II signal transduction. Curr. Pharm. Biotechnol. 2, 81-86.

Takahashi, N. and Smithies, O. (2004). Human genetics, animal models and computer simulations for studying hypertension. Trends Genet. 20, 136-145.

Takimoto, E., Champion, H. C., Li, M. et al. (2005). Oxidant stress from nitric oxide synthase-3 uncoupling stimulates cardiac pathologic remodeling from chronic pressure load. $J$. Clin. Invest. 115, 1221-1231.

Tang, K. M., Wang, G. R., Lu, P. et al. (2003). Regulator of Gprotein signaling-2 mediates vascular smooth muscle relaxation and blood pressure. Nature Med. 12, 1506-1512.

Tesson, L., Cozzi, J., Menoret, S . et al. (2005). Transgenic modifications of the rat genome. Transgenic Res. 14, 531-546.

Touyz, R. M. and Schiffrin, E. L. (2006). Peroxisome proliferator-activated receptors in vascular biology-molecular mechanisms and clinical implications. Vascul. Pharmacol. 45, 1928.

Touyz, R. M. (2004). Reactive oxygen species, vascular oxidative stress, and redox signaling in hypertension: what is the clinical significance? Hypertension 44, 248-252.

Ushikubi, F., Sugimoto, Y., Ichikawa, A. and Narumiya, S. (2000). Roles of prostanoids revealed from studies using mice lacking specific prostanoid receptors. Jpn.J. Pharmacol. 83, 279-285

Veerasingham, S. J., Sellers, K. W. and Raizada, M. K. (2004). Functional genomics as an emerging strategy for the investi- 
gation of central mechanisms in experimental hypertension. Prog. Biophys. Mol. Biol. 84, 107-123.

Walsh, D. A. and McWilliams, D. F. (2006). Tachykinins and the cardiovascular system. Curr. Drug Targets. 7, 1031-1042.

Wang, L., Menendez, P., Cerdan, C. and Bhatia, M. (2005). Hematopoietic development from human embryonic stem cell lines. Exp. Hematol. 33, 987-996.

Watson, R. E., Supowit, S. C., Zhao, H. et al. (2002). Role of sensory nervous system vasoactive peptides in hypertension. Braz. J. Med, Biol.Res. 35, 1033-1045.

Wilcox, C. S. (2005). Oxidative stress and nitric oxide deficiency in the kidney: a critical link to hypertension? Am. J. Physiol. Regul. Integr. Comp. Physiol. 289, R913-935.

Wilcox, C. S. (2006). Special feature: Cardiovascular-kidney interactions in health and disease. Am. J. Physiol. Regul. Integr. Comp. Physiol. 290, R34-36.

Williams, M. (2003). Target validation. Curr. Opin. Pharmacol. 3, 571-577.

Wu, L. and Wang, R. (2005). Carbon monoxide: endogenous production, physiological functions, and pharmacological applications. Pharmacol. Rev. 57, 585-630.

Yagil, Y. and Yagil, C. (2001). Genetic models of hypertension in experimental animals. Exp. Nephrol.9, 1-9.

Yang, Z., Sibley, D. R. and Jose, P. A. (2004). D5 dopamine receptor knockout mice and hypertension. J. Recept. Signal Transduct. Res. 24, 149-164.

Yasunari, K., Maeda, K., Nakamura, M. et al. (2005). Left ventricular hypertrophy and angiotensin II receptor blocking agents. Curr. Med. Chem. Cardiovasc. Hematol. Agents 3, 61-67.

Vauquelin, G., Michotte, Y., Smolders, I. et al. (2002). Cellular targets for angiotensin II fragments: pharmacological and molecular evidence. J. Renin Angiotensin Aldosterone Syst. 3, 195-204.

Zambrowicz, B. P. and Sands, A. T. (2003). Knockouts model the 100 best-selling drugs - will they model the next 100 ? Nat. Rev. Drug. Discov. 2, 38-51.

Zeng, C., Felder, R. A., Jose, P. A. (2006). A new approach for treatment of hypertension: modifying D1 dopamine receptor function. Cardiovasc. Hematol. Agents Med. Chem. 4, 369377.

Zeng, C., Sanada, H., Watanabe, H. et al. (2004). Functional genomics of the dopaminergic system in hypertension. Physiol. Genomics 19, 233-246.

Zhang, P., Xu, X., Hu, X. et al. (2007). Inducible nitric oxide synthase deficiency protects the heart from systolic overloadinduced ventricular hypertrophy and congestive heart failure. Circ. Res. 100, 1089-1098.

Zhu, Y. C., Zhu, Y. Z. and Moore, P. K. (2006). The role of urotensin II in cardiovascular and renal physiology and diseases. Br. J. Pharmacol. 148, 884-901.

\section{Acknowledgements}

We would like to sincerely thank the Swiss organisation "Animal-free Research", Zurich, Switzerland, previously called "Fonds für versuchstierfreie Forschung," without whose generous support this investigation could not have been undertaken. Mr. Manfred Schmitt was of great assistance in the improvement of this text.

\section{Correspondence to}

Prof. Dr. Toni Lindl

Institut für angewandte Zellkultur

Balanstr. 6

81669 München

Germany

e-mail: I-A-Z@t-online.de

www.I-A-Z-Zellkultur.de 